\title{
CARACTERIZAÇÃO DAS PÓS- GRADUAÇÕES LATO SENSU, NA MODALIDADE A DISTÂNCIA, EM EDUCAÇÃO AMBIENTAL NO BRASIL
}

Ivan Carlos da Costa Barbosa ${ }^{1}$

Resumo: A literatura não apresenta dados sobre o panorama dos cursos de pós-graduação em educação ambiental lato sensu, na modalidade à distância. $\mathrm{O}$ presente texto tem como finalidade realizar uma caracterização dos cursos cadastrados como ativos na base de dados do Ministério da Educação (eMEC). Este estudo permitiu mostrar que nos últimos anos houve um aumento no numero de instituições de ensino superior que ofertam este tipo de curso. Os cursos com melhor desempenho se encontram nas regiões Sul e Sudeste, a natureza administrativa privada é a predominante. Espera-se, então, contribuir para a ampliação do conhecimento sobre as circunstâncias nas quais os cursos de especialização EAD em EA têm sido ofertados no Brasil.

Palavras-chave: Base de Dados e-MEC; Educação à Distância; Curso de Nível Superior. 


\section{Introdução}

Devido à globalização, os avanços tecnológicos e ao risco do desemprego que a atual crise econômica gerou em todo o mundo, o mercado de trabalho vem se tornando mais competitivo e exigente. Na chamada Era da Informação, as pessoas não estão apenas valorizando a comunicação fácil, principalmente pela rede mundial de computadores, mas também há uma grande preocupação com a atualização do conhecimento (SILVA et al., 2009).

A Educação a Distância (EAD) é uma maneira de ensino que permite atingir um número significativo de pessoas. Ela rompe com a forma tradicional de ensino e aponta para um novo paradigma. A EAD seria uma forma de ensinar e aprender que proporciona ao aluno que não possui condições de comparecer diariamente à escola a oportunidade de se apropriar dos conteúdos que são transmitidos aos estudantes da educação presencial. Uma forma que possibilita a eliminação de distâncias geográficas e temporais ao proporcionar ao aluno a organização do seu tempo e local de estudos (HACK, 2011).

Em atmosfera de intenso debate quanto ao papel e às finalidades da pós-graduação e da qualidade de suas propostas acadêmicas, num tempo em que se demanda desses cursos que respondam à grande variedade de desafios sociais, tecnológicos, políticos e ecológicos, é de grande importância refletir sobre as condições atuais e o futuro desejável para os mesmos (GATTI, 2001, p. 108).

Os cursos de pós-graduação lato sensu, embora oferecidos em alguns casos sob a forma de extensão, assumem dominantemente as formas de aperfeiçoamento e especialização e constituem uma espécie de prolongamento da graduação. De fato, esses cursos visam a um aprimoramento (aperfeiçoamento) ou aprofundamento (especialização) da formação profissional básica obtida no curso de graduação correspondente (SAVIANI, 2000, p. 1). No entanto, a partir do final dos anos 1990, esses cursos, embora conferissem certificação de especialização, foram sendo negligenciados pela normatização e pelo processo de avaliação da Coordenação de Aperfeiçoamento de Pessoal de Nível Superior (Capes) (SAVIANI, 2000, p. 1).

A questão ambiental é um tema que vem sendo abordado frequentemente em nosso dia a dia, seja nos meios de comunicação, nas escolas, nas empresas, ou até mesmo em conversas entre amigos (ROOS; BECKER, 2012, p. 857). Leff (2001) afirma que a escola é um dos elementos para que Educação Ambiental (EA) se efetive. Diante das graves injustiças socioambientais com as quais nos deparamos e da exigência de respostas rápidas e de âmbito global às mesmas, é fundamental que a EA possa ser viabilizada através de modalidades de ensino cada vez mais eficientes de modo a atingir com brevidade a um número cada vez maior de pessoas (CARVALHO, 2012).

Com base no que foi apresentado, o presente texto tem como finalidade realizar uma caracterização dos cursos de pós-graduação Lato 
sensu, na modalidade à distância, em Educação Ambiental cadastrados como ativos na base de dados do Ministério da Educação (e-MEC) e identificar a situação atual da oferta destes cursos.

\section{EAD: Especializações em Educação Ambiental No Brasil}

\section{A Educação a Distância}

No contexto das sociedades atuais, a Educação a Distância surge como uma modalidade de educação que pode possibilitar formas diferentes de ver o mundo, de ensinar e aprender. Ela traz aspectos positivos ao contexto educacional, como democratização de oportunidades educacionais e possibilidade de se constituir em instrumento de emancipação do individuo no contexto social. Propicia a produção de conhecimento individual e coletivo, favorecido pelos ambientes digitais e interativos de aprendizagem (MARTINS; FROM, 2016).

A educação a distância fundamenta-se em um histórico mais antigo do que se imagina. Contudo, somente a partir da década de 1990 o processo de globalização intensificou-se em decorrência de fatores como os avanços tecnológicos (VENERAL, 2013, p. 255).

O primeiro Plano Nacional da Educação (PNE 2001-2010) (BRASIL, 2001) estabelecia que ao final daquela década a meta fosse alcançar $30 \%$ da taxa líquida de matrículas de jovens entre 18 e 24 anos no Ensino Superior. Entretanto, dados do Instituto Brasileiro de Geografia e Estatística/Pesquisa Nacional por Amostra de Domicílios (IBGE, 2015) demonstram que o percentual é de apenas $16,5 \%$ da população nessa faixa etária, portanto, bem distante do objetivo anterior e da meta do novo Plano Nacional da Educação (PNE 2014-2024) que é alcançar o percentual de 33\% da taxa líquida e 50\% da taxa bruta de matrículas nessa faixa etária, sendo que esta expansão seria da ordem de $40 \%$ para o segmento público. A partir dos números atuais de matrículas existentes, significaria uma ampliação de quatro milhões de vagas, sendo cerca de 1,6 milhão apenas no segmento público (ARRUDA; ARRUDA, 2015, p. 321).

De acordo com dados do Censo da Educação Superior (BRASIL, 2013), o ensino a distância (EaD) é a modalidade de ensino que mais cresce no Brasil e a procura por cursos nessa modalidade também segue essa mesma linha (MICHELON; LIRA; RAZUCK, 2016, p. 213).

\section{Educação Ambiental}

Conforme Luckesi (2011), a educação pode ser compreendida como mediação de um projeto social. Nela há a possibilidade de agir a partir dos próprios condicionamentos históricos. Esta linha de pensamento interpreta a educação dimensionada dentro dos determinantes sociais, com possibilidades de agir estrategicamente. Portanto, a educação, nesse ponto de vista poderá 
ser reproduzida desde que também possibilite formar cidadãos críticos e poderá estar a serviço de um projeto de libertação da sociedade capitalista, a educação é visualizada assim como agente da transformação da sociedade (MARTINS; FROM, 2016).

A educação Ambiental pode ser entendida como uma metodologia em conjunto, onde cada pessoa pode assumir e adquirir o papel de membro principal do processo de ensino/aprendizagem a ser desenvolvido, desde que cada pessoa ou grupo seja agente ativamente participativo na análise de cada um dos problemas ambientais diagnosticados e com isso buscando soluções, resultados e inclusive preparando outros cidadãos como agentes transformadores, por meio do desenvolvimento de habilidades e competências e pela formação de atitudes, através de uma conduta ética, condizentes ao exercício da cidadania (ROOS; BECKER, 2012, p. 857).

A Conferência de Estocolmo em 1972 refletiu no ordenamento jurídico brasileiro e a delegação oficial brasileira após o retorno de tal evento conseguiu obter do governo federal um decreto criando a Secretaria Especial do Meio Ambiente, que iniciou suas atividades em 1974 (BORTOLON; MENDES, 2014, p. 118). A Conferência de Estocolmo estimulou no Brasil a consciência ambiental desenvolvendo uma legislação interna, sendo estas novas preocupações consagradas na Constituição da República Federativa do Brasil de 1988 em seu artigo 225, bem como pela Lei 9.795, de 27 de abril de 1999, que dispõe sobre a educação ambiental e institui a Política Nacional de Educação ambiental (BORTOLON; MENDES, 2014, p. 118).

A interface entre os campos de Educação a Distância (EAD) e de Educação Ambiental (EA) é bastante recente e ainda em fase de aperfeiçoamento. Contudo, esta vem sendo na primeira década desse novo século, cada vez mais fortalecida "constituindo novas redes culturais, resignificando compreensões de mundo e contribuindo com práticas horizontais na construção de saberes" (CARVALHO, 2010).

A ideia é tornar a Educação Ambiental e o processo de Educação a Distância mais frequentes nos sistemas educativos, assumindo funções de gerar conhecimento, através de investigações que possam substanciar uma real formação de profissionais ao longo do prazo, numa verdadeira educação permanente (LOPES; NEVES, 2014).

\section{Pós-Graduação Lato Sensu a Distância}

Vários cursos são criados e difundidos, tanto de graduação, como de pós-graduação, nas diversas áreas do conhecimento. Políticas públicas educacionais definem posicionamentos sobre o assunto, buscando estabelecer legislações específicas de incentivo a programas de Educação a Distância (MARTINS; FROM, 2016).

O Plano Nacional de Pós-Graduação - PNPG 2005-2010 (BRASIL/MEC/CAPES, 2005) dispõe que os cursos de especialização façam 
parte do sistema de pós-graduação. Pretende também que esse sistema seja expandido, com a devida capacitação do corpo docente, tanto para os cursos stricto sensu quanto para os de lato sensu, compreendendo a especialização de profissionais para o mercado de trabalho público e privado (incluindo-se aqui a capacitação de professores para os níveis básico e superior de ensino), além da formação de técnicos e pesquisadores para empresas públicas e privadas (ARRUDA; ARRUDA, 2015, p. 321).

Por se tratar de modalidade que perdura ao longo da vida, os cursos de especialização stricto e lato sensu não se restringem à dimensão pragmática de preparação direta para o trabalho ou para ascensão na carreira, como vem sendo costumeiramente compreendido pelo senso comum. A dimensão formativa do educando é requisito fundamental para a qualidade dos cursos, na medida em que prepara o indivíduo para o exercício da cidadania, que transcende o limite do campo profissional (FONSECA; FONSECA, 2016, p. 151).

\section{Educação Ambiental à Distância e oSistema e-MEC}

O lançamento do Plano de Desenvolvimento da Educação (PDE), em março de 2007, apresentou o desafio de se pensar a educação do país como sistema coerente e integrado, desde a educação básica, perpassando pela educação nos níveis profissional, tecnológico e superior, até o ensino de pósgraduação. A gestão é peça-chave para garantir a consecução dos objetivos centrais para a educação superior. Nesse sentido, são necessárias reestruturações organizacionais e desenvolvimento de novas ferramentas gerenciais para o alcance da eficiência e da eficácia das políticas que vêm sendo implementadas (BUCCl, 2006).

Nos últimos 10 anos, a oferta de cursos superiores cresceu de forma acelerada no país, impulsionado por programas e ações do Governo Federal na ampliação da oferta de vagas na educação superior, visando qualificar a educação básica do país, conforme dados do Relatório Educação para Todos no Brasil 2000-2015 (BRASIL, 2014).

Diante da constatação de que a elevação da qualidade da educação superior depende do bom funcionamento de sua regulação, em 2006, o Ministério da Educação iniciou movimento de "reinvenção processual", empreendendo esforços no sentido de: i) reformular integralmente as normas de regulação (marco legal); ii) reformular as práticas internas (fluxos de trabalho); e iii) desenvolver ferramenta gerencial eficiente (sistema informatizado). A esse movimento, que se insere numa política mais ampla de qualificação do sistema educacional, deu-se o nome de Sistema e-MEC (BUCCI, 2006).

Entretanto, a literatura não apresenta dados sobre o panorama dos cursos de pós-graduação em educação ambiental lato sensu, na modalidade à distância (LOPES; NEVES, 2014). O Relatório Analítico da Aprendizagem a Distância no Brasil, coordenado pela Associação Brasileira de Educação a Revbea, São Paulo, V. 14, № 2: 234-251, 2019. 
Distância (2016), não mostra especificamente a quantidade de cursos em Educação Ambiental, podendo esta estar diluída em outras temáticas descritas no relatório (ABED, 2017).

Esse processo é importante na identificação das Instituições de Ensino Superior, descrevendo os caminhos da Educação Ambiental no Brasil e a formação de educadores, conforme recomendado na Conferência de Tbilisi (1977), na Política Nacional de Educação Ambiental (Lei 9.795/99) e em outros documentos que delimitam diretrizes na universidade, e contribuirão na apreciação do seu papel como espaço de vinculação com a temática (LOPES; NEVES, 2014).

\section{Método de Pesquisa}

Este estudo pode ser classificado como exploratório e descritivo (GIL, 1999). Foi realizado um estudo quantitativo de base documental realizado a partir da consulta da base de dados do site do Ministério da Educação denominado e-MEC. Em um primeiro momento foram tomados como base os cursos de especializações: cadastrados entre os anos de 2005 a maio de 2018; na modalidade à distância; cujo nome tinha como palavra-chave "educação ambiental"; classificados na área de educação; e, com o status "ativo".

O resultado desta busca permitiu identificar e organizar um conjunto de 47 cursos. Sendo todos considerados para o corpus descritivo-analítico. Para tanto, os tópicos foram avaliados, conforme critério do sistema de dados: nomenclatura do curso; quantidade de cursos por região; natureza/categoria administrativa da Instituição de Ensino Superior (IES); quantidade de cursos iniciados por ano; periodicidade de oferta do curso; quantidade de cursos por carga horária; duração do curso (em meses); quantidade de vagas ofertadas; e, distribuição dos cursos sem conceito, segundo os conceitos insatisfatórios (Conceito 1 e 2) e conceitos satisfatórios (Conceito 3, 4 e 5).

A organização e análise dos dados obtidos foram orientadas através da estatística descritiva com a obtenção de frequências $(f)$ e porcentagens (\%). Os resultados foram discutidos conforme a literatura atual.

\section{Resultados e Discussão}

Todos os níveis acadêmicos dispõem de ofertas de (EAD) no país. A grande maioria dos cursos ofertados em cursos regulamentados totalmente a distância são especializações lato sensu, com uma oferta de 1.098 cursos. Com uma grande distância, também há 235 ofertas de cursos em nível tecnológico, 219 em nível técnico profissionalizante e 210 ofertas de licenciaturas. Chama atenção a diferença entre a oferta de cursos totalmente a distância e semipresenciais na pós-graduação lato sensu - em que há apenas 109 cursos semipresenciais em comparação com 1.098 cursos totalmente a distância - e no doutorado, que não conta com oferta semipresencial (ABED, 2017).

revista brasileira educação ambiental 
A análise dos dados obtidos através da consulta do banco de dados do MEC permitiu identificar as nomenclaturas para os cursos de especialização na modalidade a distância em Educação Ambiental na área de educação ofertados pelas IES cadastradas. A Figura 1 apresenta os nomes usuais destes cursos.

Foi identificado que, aproximadamente, $49 \%$ dos cursos possuem em seu nome apenas a expressão "Educação Ambiental", enquanto os demais cursos relacionam a expressão "Educação Ambiental" à docência (aproximadamente 9\%) ou a outras expressões (Desenvolvimento sustentável, Sustentabilidade, entre outros) (aproximadamente $43 \%$ ).

A quase totalidade dos cursos de especialização lato sensu em Educação Ambiental ofertados apresenta na sua nomenclatura apenas o termo Educação Ambiental ou com o termo associado a outros. Dentre estes, um número pequeno de cursos relaciona a Educação Ambiental a docência. De acordo com Said (SAID; SANTOS, 2017, p. 1), é sabido que hoje a educação ambiental é implantada na maioria das escolas por meio de projetos e trabalhos em grupos, no intuito de promover uma conexão com os alunos, muitas vezes, com ênfase na preservação e sustentabilidade do meio ambiente. Logo, é necessário que a oferta de cursos em Educação Ambiental voltados para a docência seja ampliada.

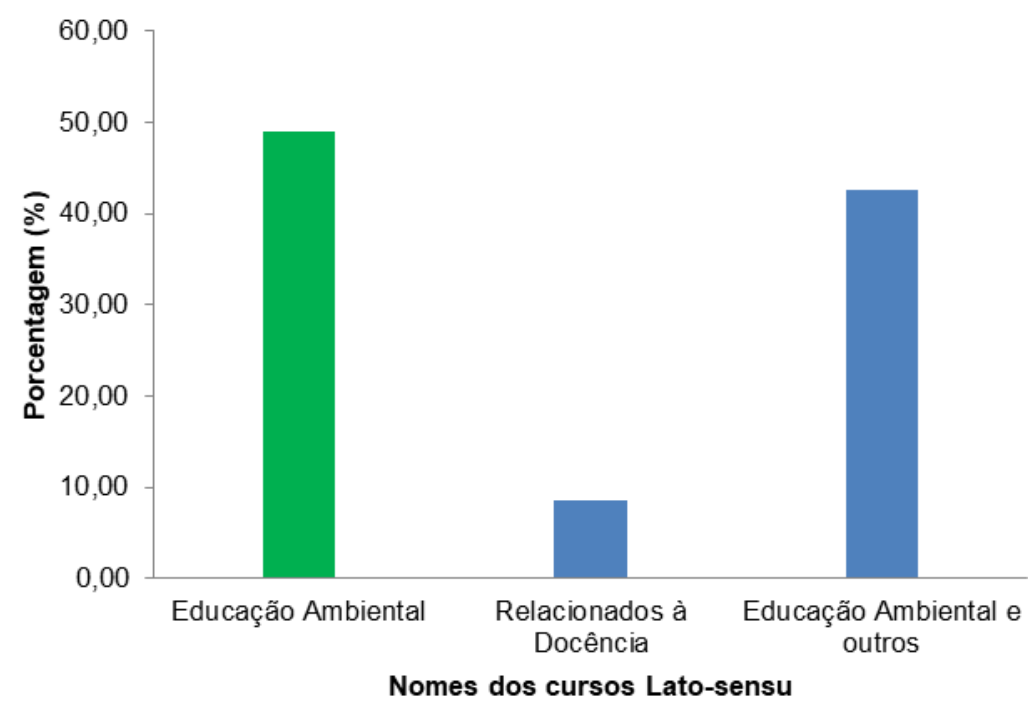

Figura 1: Nomenclatura dos cursos de especialização à distância relacionados à Educação Ambiental das IES.

Fonte: Autoria própria a partir da base de dados do e-MEC (2018).

Outra unidade de análise identificada no estudo foi a quantidade de cursos cadastrados segundo as regiões do Brasil, como exposto na Figura 2. 


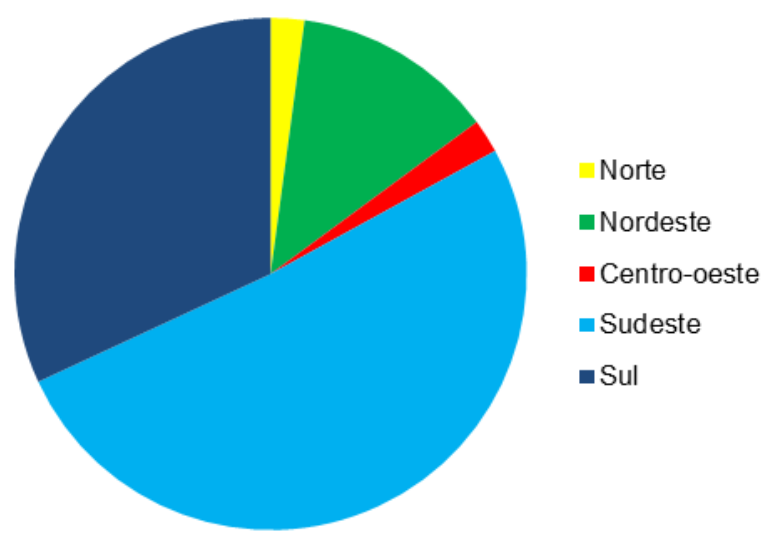

Figura 2: Distribuição dos cursos de especialização à distância relacionados à Educação Ambiental das IES.

Fonte: Autoria própria a partir da base de dados do e-MEC (2018).

É importante destacar que esta distribuição está relacionada à Unidade Federativa a qual pertence a IES. A região Sudeste compreende $51 \%$ dos cursos ofertados, seguida pela região Sul com 32\%, região Nordeste com $13 \%$ e as regiões Norte e Centro-Oeste com $2 \%$ cada.

Quanto à região na qual se localiza a sede administrativa da IES verifica-se uma concentração destas nas Regiões Sul e Sudeste do Brasil. Esse dado revela como a educação a distância é um segmento bem distribuído pelo território nacional, conforme expõe o Relatório Analítico da Aprendizagem a Distância no Brasil do ano de 2016 (ABED, 2017). Este relatório identificou a seguinte distribuição das IES por região: $37 \%$ para a Região Sudeste, 27\% para a Região Sul, $18 \%$ para a Região Nordeste, $11 \%$ para a Região CentroOeste e $7 \%$ para a Região Norte. Um resultado muito semelhante ao encontrado nesta pesquisa quando se especifica somente as IES que ofertam cursos lato sensu, à distância, em Educação Ambiental.

A base de dados de consulta classificou as instituições em categorias: privada com fins lucrativos, privada sem fins lucrativos e pública federal. A Figura 3 apresenta a porcentagem de IES cadastradas que ofertam o curso de pós-graduação Lato sensu em Educação Ambiental. 


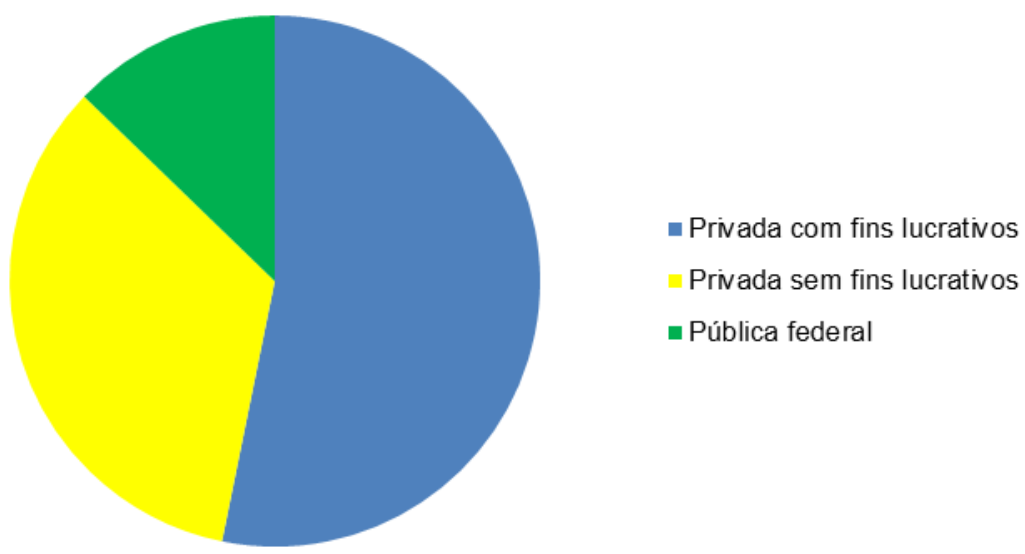

Figura 3: Distribuição das IES com cursos de especialização à distância relacionados à Educação Ambiental por categoria administrativa.

Fonte: Autoria própria a partir da base de dados do e-MEC (2018).

Posteriormente ao processo avaliativo, foi identificada a partir da Figura 3 a expressiva presença do setor privado na formação continuada em Educação Ambiental (um total de $87 \%$, sendo $53 \%$ privada com fins lucrativos e $34 \%$ privada sem fins lucrativos). Sendo possível também possível afirmar que $13 \%$ das IES são classificadas como pública federal.

A maior parte das IES é categorizada administrativamente como privada (com ou sem fins lucrativos). Segundo Arruda e Arruda (2015, p. 321), as iniciativas no âmbito da educação pública à distância historicamente foram pontuais, sem muita articulação entre a União, os estados e os municípios. O texto do PNE 2001-2010 faz ainda elogios discutíveis sobre as iniciativas privadas no âmbito da $\mathrm{EaD}$, em uma clara alusão à produção de programas educativos televisivos, entretanto, pouco se fala a respeito das iniciativas públicas.

O Censo EAD.BR 2016 (ABED, 2017) contou com a participação de todas as categorias administrativas consultadas. $O$ maior grupo de respondentes são as instituições educacionais privadas com fins lucrativos, com 106 respondentes, que correspondem a 34\% da amostra. Em seguida, temos as instituições privadas sem fins lucrativos, com 64 respondentes, correspondendo a $21 \%$ da amostra. Dentre as instituições educacionais públicas, a maioria são as federais, com 54 respostas, o que corresponde a $17 \%$ da amostra, seguidas de 26 estaduais e 6 municipais.

A Figura 4 apresenta a distribuição da criação dos cursos de pósgraduação Lato sensu em Educação Ambiental, na modalidade à distância, entre os anos de 2005 a maio de 2018. 


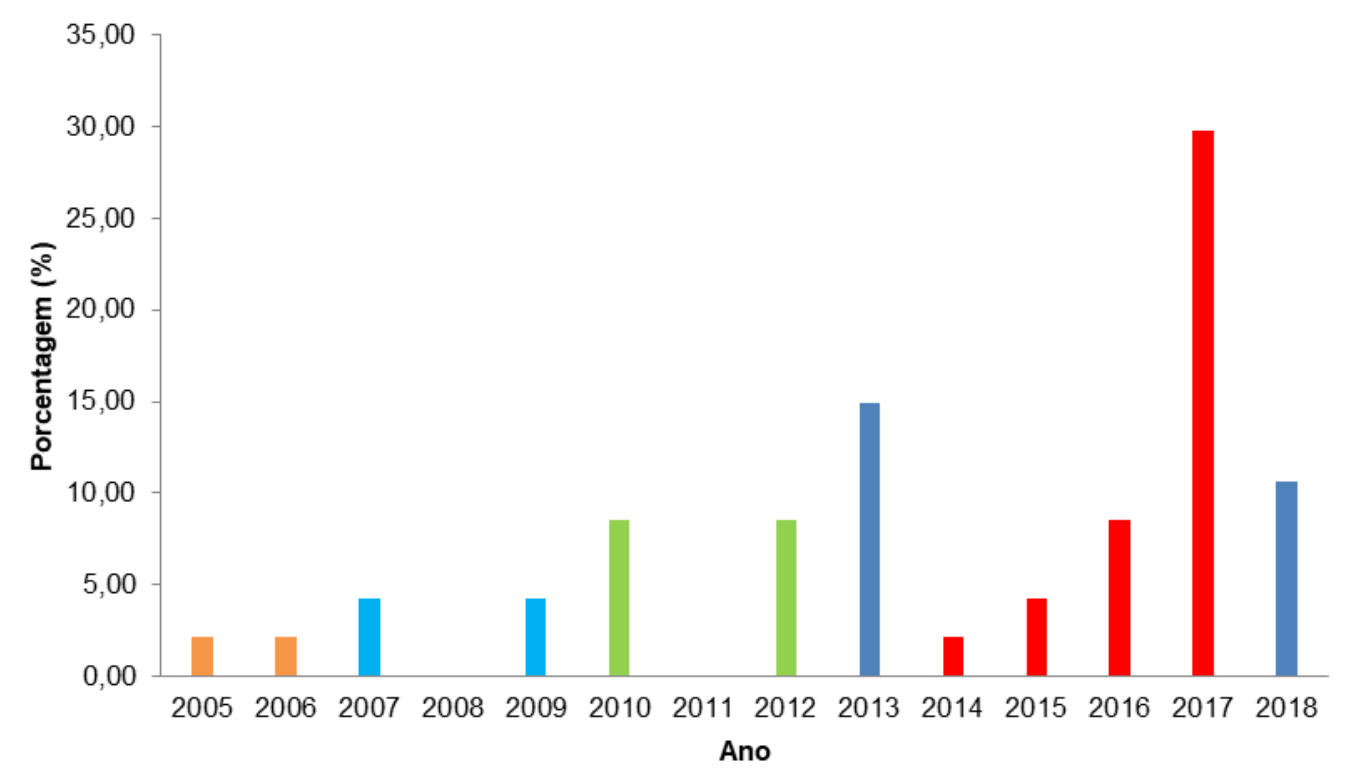

Figura 4: Distribuição da criação dos cursos de especialização à distância relacionados à Educação Ambiental entre os anos de 2005 e maio de 2018.

Fonte: Autoria própria a partir da base de dados do e-MEC (2018).

Nos anos de 2008 e 2011 não ocorreu a criação de nenhum curso. Os anos de 2005 e 2006 ambos com 2,13\%; 2007 e 2009 ambos com 4,26\%; e, 2010 e 2012 ambos com 8,51\%; mantiveram o mesmo perfil em termos de quantidade de cursos. Destaca-se o crescimento de 6,4\% do ano de 2012 (8,51\%) para $2013(14,89 \%)$. Entre os anos de 2014 e 2017 é possível observar o acréscimo na quantidade de cursos $(2,13 \%, 4,26 \%, 8,51 \%$ e 29,49\%, para os anos de 2014, 2015, 2016 e 2017, respectivamente). Para o ano de 2018, a porcentagem de cerca de $11 \%$ corresponde aos cursos cadastrados até o momento da pesquisa (maio de 2018).

De acordo com Arruda e Arruda (2015, p. 321):

Do ponto de vista histórico, a EaD no Brasil pode ser relacionada ao início do século XIX, entretanto, o seu marco regulatório ocorre com a promulgação da Lei no 9.394 de 1996 (Diretrizes e Bases da Educação - LDB), conforme estabelecido no Art. 80. A regulamentação desse artigo deu-se inicialmente pelo Decreto $\mathrm{n}^{\circ} \mathbf{2 . 4 9 4}$, de 10 de fevereiro de 1998, que trazia em seu texto interpretações confusas e controversas sobre a EaD. A partir da emergência do governo de Luiz Inácio Lula da Silva em 2003, o Decreto № 2.494 de 1998 é revogado pelo decreto no 5.622, de 19 de dezembro de 2005, cujo texto aprovado apresentou melhorias na definição da EaD, bem como um conjunto de artigos mais claros a respeito da sua organização e funcionamento. O decreto no 5.622/2005 possibilitou a oferta de cursos à distância em todos os níveis. 
Do banco de dados também foram consultadas as periocidades de cada curso e estas foram categorizadas e quantificadas em eventuais ou regulares. A Figura 5 apresenta a porcentagem de periocidade dos cursos.

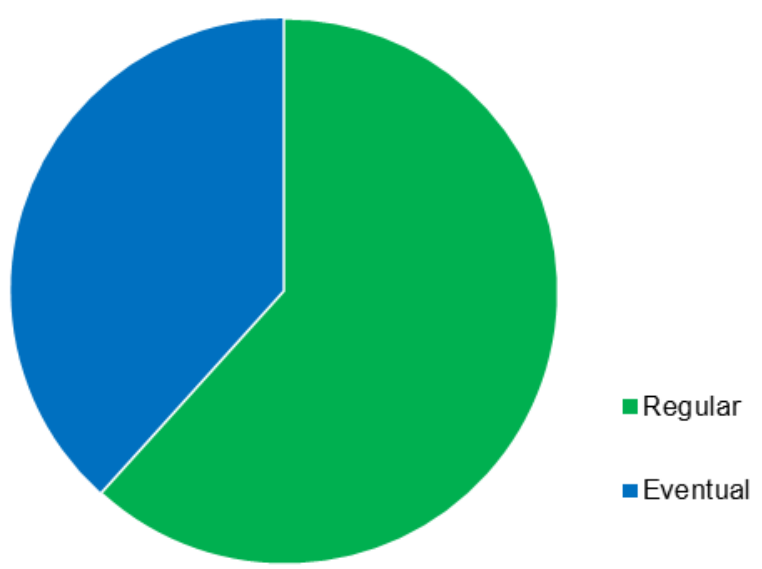

Figura 5: Distribuição da periocidade dos cursos de especialização à distância relacionados à Educação Ambiental.

Fonte: Autoria própria a partir da base de dados do e-MEC (2018).

A Figura 5 demonstra que $62 \%$ dos cursos são ofertados de forma regular pelas IES. Um total de $38 \%$ é ofertado eventualmente. Também após análise dos dados obtidos é possível destacar que a maior parte (4 das 6 identificadas) das IES categorizadas como pública federal oferta o curso de especialização, na modalidade à distância, em Educação Ambiental com periocidade eventual.

A facilitação da oferta de cursos de forma regular, principalmente por instituições privadas, está associada possivelmente à diminuição de custos referentes à oferta dos cursos. Segundo Arruda e Arruda (2015), uma vez que a compreensão da EaD como processo de "autoaprendizagem" incorre na baixa valorização dos docentes e na centralidade em materiais didáticos como elementos mediadores da educação. Além disso, as exigências quanto à estrutura física para a oferta de cursos superiores à distância são ambíguas e a sua fiscalização praticamente inexistente, por não haver legislação especifica.

$\mathrm{Na}$ Figura 6 estão expostas as porcentagens de cursos por faixa de carga horária total.

Através destas informações destaca-se que um quantitativo de $17 \%$ dos cursos oferta o curso com a carga horária mínima estabelecida em lei (BRASIL, 1996). Os demais cursos (aproximadamente 83\%) ofertam os cursos com carga horária superior ao mínimo de $360 \mathrm{~h}$. Sendo que, mais da metade deste quantitativo (47\%) ofertam os cursos com carga horária acima de $360 \mathrm{~h}$ até $450 \mathrm{~h}$. Entre os mais longos, um total de cerca de $27 \%$ oferta o curso com carga horária entre 451 e 599h e um total de $9 \%$ oferta com carga horária de $600 \mathrm{~h}$ ou mais.

Revbea, São Paulo, V. 14, № 2: 234-251, 2019. 


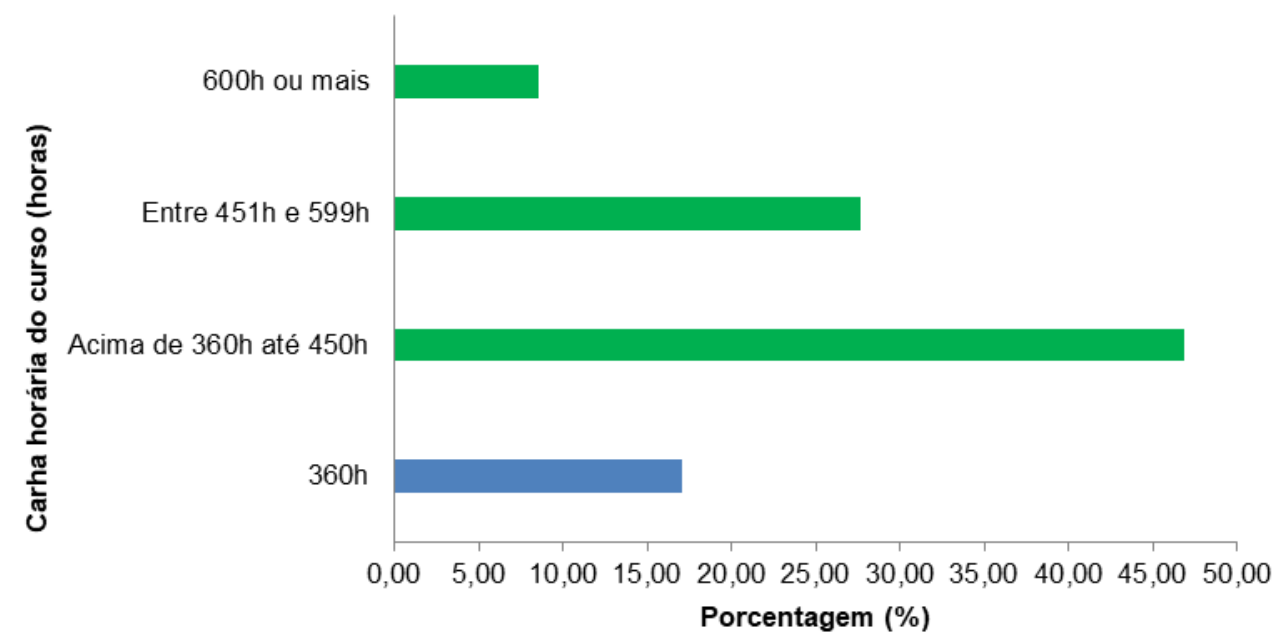

Figura 6: Distribuição dos cursos de especialização à distância relacionados à Educação Ambiental por faixa de carga horária total.

Fonte: Autoria própria a partir da base de dados do e-MEC (2018).

Os cursos ofertados têm a sua carga horária dividida em uma determinada quantidade de meses. Neste período o aluno deverá concluir a pós-graduação, que se finaliza com a apresentação do trabalho de conclusão do curso (TCC). A Figura 7 apresenta a distribuição dos cursos conforme a duração (em meses).

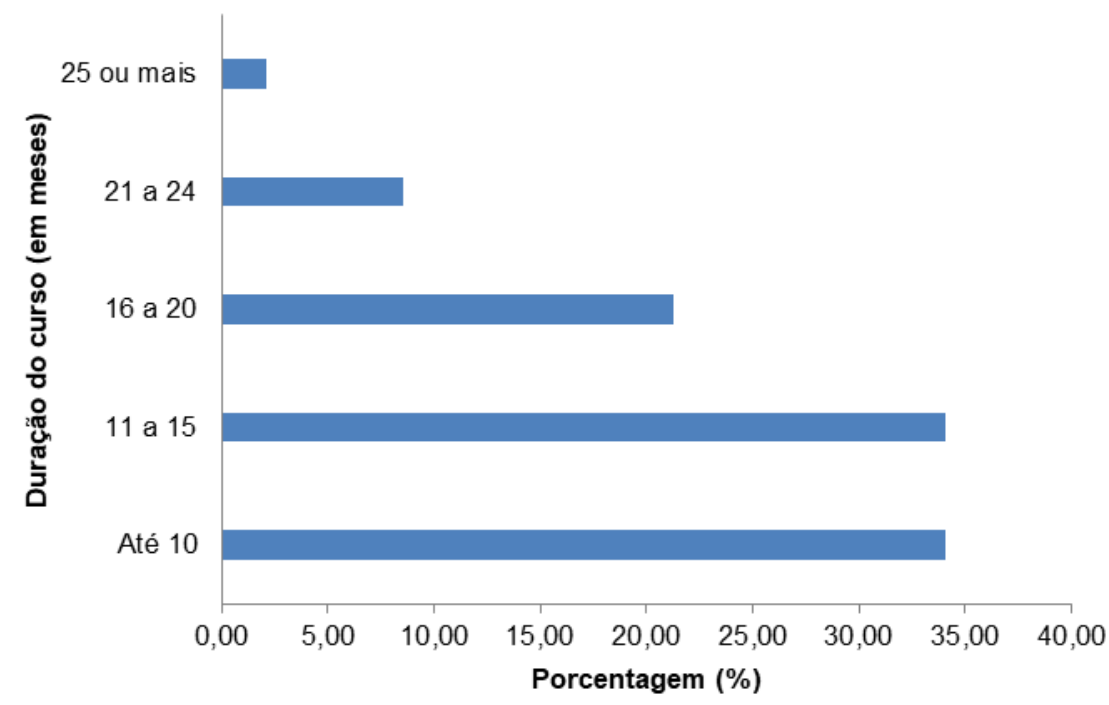

Figura 7: Distribuição dos cursos de especialização à distância relacionados à Educação Ambiental por duração (em meses).

Fonte: Autoria própria a partir da base de dados do e-MEC (2018).

Com base na Figura 7 destaca-se que $34 \%$ dos cursos possuem uma duração de até 10 meses. O mesmo percentual de cursos com duração entre Revbea, São Paulo, V. 14, № 2: 234-251, 2019. 
11 e 15 meses. Um total de $21 \%$ dos cursos possui duração entre 16 a 20 meses, $9 \%$ dos cursos com duração entre 21 a 24 meses e $2 \%$ com duração de 25 ou mais meses. De acordo com os dados obtidos foi observado que os cursos com 600 horas ou mais de carga horária estão incluídos na categoria de cursos com até 10 meses de duração. Sendo que o curso com a maior carga horária $(720 \mathrm{~h})$ deve ser concluído em até 6 meses. Os cursos com a carga horária mínima de 360 horas apresentam duração variando de 6 a 16 meses para sua conclusão.

A Figura 8 apresenta a distribuição dos cursos segundo a quantidade de vagas ofertadas por turma.

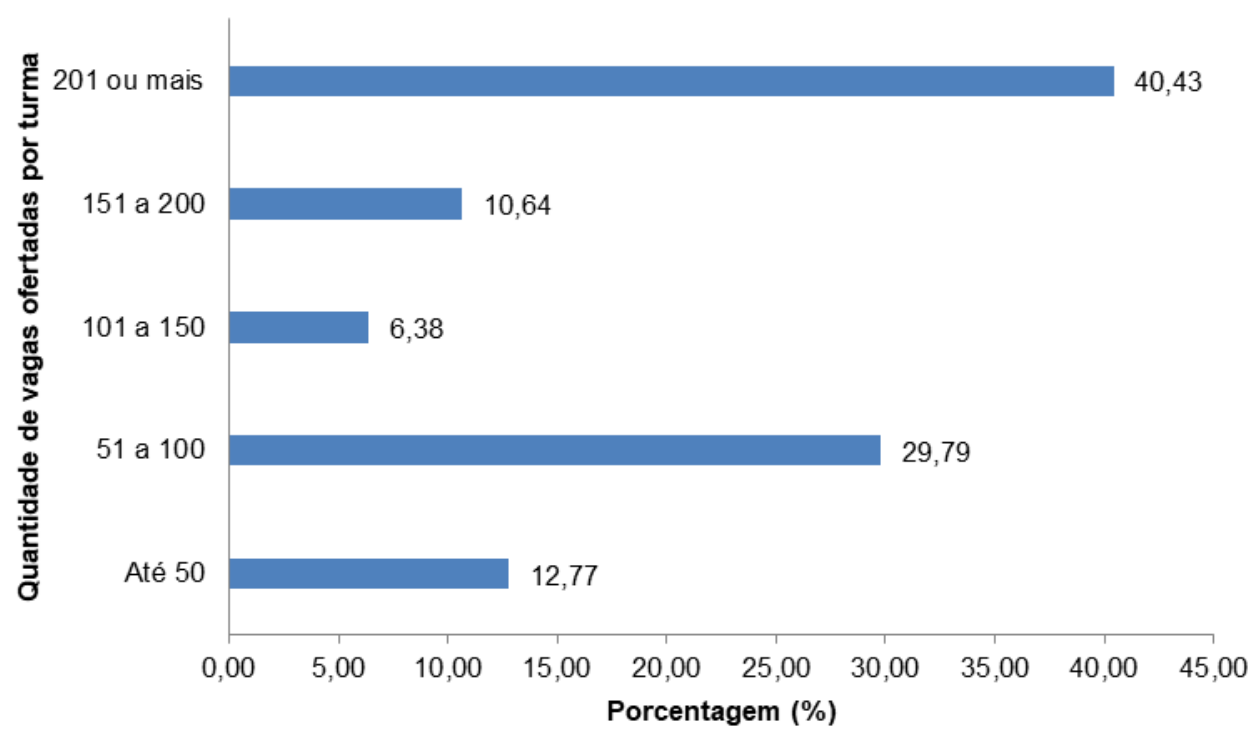

Figura 8: Distribuição dos cursos de especialização à distância relacionados à Educação Ambiental por quantidade de vagas ofertadas por turma.

Fonte: Autoria própria a partir da base de dados do e-MEC (2018).

Através da figura é possível observar mais da metade dos cursos (57\%) oferta acima de 100 vagas por turma. Sendo que, cerca de $40 \%$ dos cursos ofertam acima de 200 vagas, cerca de $11 \%$ oferta entre 151 a 200 vagas e cerca de $6 \%$ oferta de 101 a 150 vagas. O restante é composto por $30 \%$ dos cursos que ofertam entre 51 a 100 vagas e $13 \%$ dos cursos que ofertam até 50 vagas.

Por não apresentar restrição de espaço físico, teoricamente a EAD não precisa ter limitação no tamanho dos grupos de alunos que participam de um curso, desde que haja professores e tutores para acompanhar a todos. Segundo o Censo EAD.BR 2016 (ABED, 2017), para todos os cursos investigado a maior parte das instituições formadoras organiza seus estudantes em grupos de até 30 integrantes, ou entre 31 e 50 alunos. Existem turmas com mais de 100 e 500 alunos, bem como as inseridas na modalidade "Sem limites" 
ou "Outra". Os grupos de mais de 500 alunos só ocorrem nas instituições privadas com e sem fins lucrativos e nas instituições do SNA.

A Tabela 1 apresenta a análise da quantidade de IES avaliadas segundo as regiões do Brasil, para os conceitos institucionais (Cl) e a Tabela 2 os conceitos institucionais EAD (CI-EAD). É importante destacar que a avaliação foi realizada de acordo com o último conceito designado a IES. Também é importante saber que nos casos em que alguma instituição oferta-se mais de um curso com a designação Educação Ambiental está somente foi contabilizada uma única vez.

Tabela 1: Distribuição dos cursos de especialização à distância relacionados à Educação Ambiental avaliados como tipificação "Sem conceito" e por Conceito Institucional (Cl).

\begin{tabular}{ccccccccccc}
\hline & \multicolumn{2}{c}{ Norte } & \multicolumn{2}{c}{ Nordeste } & \multicolumn{2}{c}{ Centro-Oeste } & \multicolumn{2}{c}{ Sudeste } & \multicolumn{2}{c}{ Sul } \\
Conceito & $f$ & $\%$ & $f$ & $\%$ & $f$ & $\%$ & $f$ & $\%$ & $f$ & $\%$ \\
\hline Sem & - & - & - & - & - & - & 1 & 6,2 & 1 & 9,1 \\
conceito & & & & & & & & & & - \\
1 & - & - & - & - & - & - & - & - & - & - \\
2 & - & - & - & - & - & - & - & - & - & - \\
3 & 1 & 100,0 & 1 & 33,3 & 1 & 100,0 & 8 & 50,0 & 5 & 45,4 \\
4 & - & - & 2 & 66,7 & - & - & 5 & 31,3 & 4 & 36,4 \\
5 & - & - & - & - & - & - & 2 & 12,5 & 1 & 9,1 \\
Total & 1 & 100,0 & 3 & 100,0 & 1 & 100,0 & 16 & 100,0 & 11 & 100,0 \\
\hline \hline
\end{tabular}

Fonte: Autoria própria a partir da base de dados do e-MEC (2018).

Excetuando-se duas IES (uma na Região Sul e outra na Região Sudeste) que foram classificadas Sem Conceito, 30 instituições obtiveram Conceitos Institucionais entre 3 e 5 . Logo, nenhuma instituição recebeu $\mathrm{Cl}$ (1 e 2) insatisfatório. Para as regiões Norte e Centro-Oeste somente foram identificadas uma instituição em cada região ofertando o curso de especialização à distância em Educação Ambiental.

Estas instituições obtiveram na última avaliação realizada pelo MEC o $\mathrm{Cl}$ igual a 3. Na Região Nordeste das 11 instituições, a maioria (66,7\%) recebeu $\mathrm{Cl}$ igual a 4. Nas regiões Sudeste e Sul foram encontradas as maiores quantidades de IES ofertando o curso especialização em Educação Ambiental à distância. Sendo que, tanto para a Região Sudeste $(50,0 \%)$ como a Região Sul $(45,4 \%)$ a maior quantidade de instituições recebeu $\mathrm{Cl}$ igual a 3. 
Tabela 2: Distribuição dos cursos de especialização à distância relacionados à Educação Ambiental avaliados como tipificação "Sem conceito" e por Conceito Institucional-EAD (CIEAD).

\begin{tabular}{ccccccccccc}
\hline \hline & \multicolumn{2}{c}{ Norte } & \multicolumn{2}{c}{ Nordeste } & \multicolumn{2}{c}{ Centro-Oeste } & \multicolumn{2}{c}{ Sudeste } & \multicolumn{2}{c}{ Sul } \\
Conceito & $f$ & $\%$ & $f$ & $\%$ & $f$ & $\%$ & $f$ & $\%$ & $f$ & $\%$ \\
\hline $\begin{array}{c}\text { Sem } \\
\text { conceito }\end{array}$ & - & - & 2 & 66,7 & 1 & 100,0 & 6 & 37,5 & 4 & 36,4 \\
1 & - & - & - & - & - & - & - & - & - & - \\
2 & - & - & - & - & - & - & - & - & - & - \\
3 & 1 & 100,0 & - & - & - & - & 3 & 18,7 & 1 & 9,1 \\
4 & - & - & 1 & 33,3 & - & - & 5 & 31,3 & 6 & 54,5 \\
5 & - & - & - & - & - & - & 2 & 12,5 & - & - \\
Total & 1 & 100,00 & 3 & 100,00 & 1 & 100,00 & 16 & 100,00 & 11 & 100,00 \\
\hline
\end{tabular}

Fonte: Autoria própria a partir da base de dados do e-MEC (2018).

A situação é diferente quando se verifica o CI-EAD (Tabela 2), pois todas as regiões, com exceção da Região Norte, apresentaram instituições sem conceito. Representando um quantitativo de 4 instituições na Região Sul, 6 instituições na Região Sudeste e uma instituição na Região Centro-Oeste. Entre as instituições que receberam conceito pode-se verificar também CI-EAD variando entre 3 e 5 . A maioria das IES na regiões Nordeste, Sudeste e Sul receberam CI-EAD igual a 4. Na Região Norte, a única IES recebeu CI-EAD igual a 3.

O Conceito Institucional - $\mathrm{Cl}$ - é a avaliação in loco feita pelos especialistas do MEC. Em visita às instalações da instituição, eles a analisam como um todo, principalmente seu Plano de Desenvolvimento Institucional (PDI), sua gestão, políticas de pessoal, políticas para a o ensino de graduação, pós-graduação, pesquisa e extensão. A IES credenciada poderá ofertar cursos a distância dependendo do seu $\mathrm{Cl}$. Assim como, é vedada a criação de polo EaD por IES com Conceito Institucional insatisfatório (BRASIL, 2017).

\section{Considerações Finais}

O sistema do e-MEC reveste-se de importância, tendo em vista que foi desenvolvido para ambiente acessível pela internet, isso permite que o público acesse as informações sobre o andamento dos processos de trabalho, bem como a relação de instituições credenciadas e de cursos autorizados e reconhecidos, além dos dados sobre os atos autorizativos e os elementos relevantes da instrução processual.

Este estudo, ao tempo que responde ao objetivo proposto de caracterizar os cursos de pós-graduação lato sensu, à distância, em Educação Ambiental permitiu mostrar que nos últimos anos houve um aumento no numero de instituições de ensino superior que ofertam este tipo de curso, 
concentradas principalmente no setor privado. Os cursos com melhor desempenho se encontram nas regiões Sul e Sudeste, enquanto que a natureza administrativa privada com fins lucrativos é a predominante. Outro importante resultado foi a constatação de que a maioria dos cursos avaliados na categoria Sem Conceito se concentra região Sudeste. As regiões Sul e Sudeste também concentram a maioria das sedes administrativas da IES estudadas. A maior parte dos cursos tem a periodicidade regular, com carga horária acima de 360 h e uma quantidade variável (entre 50 a 2000) de alunos por turma virtual.

Espera-se, então, contribuir para a ampliação do conhecimento sobre as circunstâncias nas quais os cursos de especialização EAD em Educação Ambiental têm sido ofertados no Brasil, de maneira a trazer para discussão as características destes cursos quanto ao número de vagas, conceito institucional, periodicidade entre outras informações.

\section{Agradecimentos}

A Universidade Federal Rural da Amazônia, ao Instituto Socioambiental e dos Recursos Hídricos e ao Centro de Tecnologia Agropecuária pelo incentivo à pesquisa e desenvolvimento profissional do autor.

\section{Referências}

ARRUDA, E. P. ARRUDA, D. E. P. Educação à distância no Brasil: políticas públicas e democratização do acesso ao ensino superior. Educação em Revista, Belo Horizonte, v. 31, n. 3, p. 321-338, 2015.

ASSOCIAÇÃO BRASILEIRA DE EDUCAÇÃO A DISTÂNCA (ABED). Censo EAD.BR: relatório analítico da aprendizagem a distância no Brasil 2016. Curitiba: InterSaberes, 2017.

BORTOLON, B.; MENDES, M. S. S. A importância da educação ambiental para o alcance da sustentabilidade. Revista Eletrônica de Iniciação Científica, Itajaí, v. 5, n. 1, p. 118-136, 2014.

BRASIL. Portaria normativa no 11, de 20 de junho de 2017. Diário Oficial da República Federativa do Brasil, Poder Executivo, Brasília, DF, 21 jun. 2017. Seção 1, p. 14-16.

BRASIL. Ministério da Educação. Relatório Educação para Todos no Brasil 2000-2015, 2014. Disponível em: http://portal.mec.gov.br/index.php?option $=$ com docman\&view $=$ download\&alias $=15774$-ept-relatorio-06062014\&category slug=junho-2014-pdf\&ltemid=30192 > . Acesso em: 22 mar. 2018.

BRASIL. Referenciais de qualidade para educação superior a distância. Portal do Ministério da Educação, 2007. Disponível em: <http://portal.mec.gov.br /seed/arquivos/pdf/legislacao/refead1.pdf>. Acesso em: 18 de mar. de 2018. 
BRASIL. Ministério da Educação. Plano Nacional de Educação. Lei oㅜ 10.192, de 09 de janeiro de 2001. Disponível em: < http://portal.mec.gov.br/arquivos/ pdf/L10172.pdf>. Acesso em: 18 de mar. de 2018.

BRASIL. Lei de Diretrizes e Bases da Educação Nacional. Lei no 9.394, de 20 de dezembro de 1996. Disponível em: < http://www.planalto.gov.br/ ccivil 03/Leis/19394.htm>. Acesso em: 18 de mar. de 2018.

BUCCI, M. P D. Experiência: Sistema e-MEC: reinvenção processual da educação superior em três dimensões da gestão pública - jurídica, organizacional e tecnológica. Inovação na Gestão Pública Federal, 2006. Disponível em: <http://repositorio.enap.gov.br/bitstream/1/263/1/103 09 eMec.pdf $>$. Acesso em: 17 de mar. de 2018.

CARVALHO, V. S. Quando a educação ambiental e a educação à distância se encontram no ensino superior. In: Congresso Internacional de Educação a Distância, 18, 2012, São Luís. Anais eletrônicos... São Luís: MA, 2012. Disponível em: <http://www.abed.org.br/congresso2012/anais/24c.pdf>. Acesso em: 16 de mar. de 2018.

BRASIL. Possibilidades da interface educação ambiental/educação a distância: uma experiência no curso a distância de graduação em Pedagogia. In: Congresso Internacional de Educação a Distância, 16, 2010, Foz do Iguaçu. Anais eletrônicos... Foz do Iguaçu: PR, 2010. Disponível em: $<$ http://www.abed.org.br/congresso2010/cd/3042010120600.pdf >. Acesso em: 15 de mar. de 2018.

FONSECA, M.; FONSECA, D. M. A gestão acadêmica da pós-graduação lato sensu: o papel do coordenador para a qualidade dos cursos. Educação e Pesquisa, São Paulo, v. 42, n. 1, p. 151-164, 2016.

GATTI, B. A. Reflexão sobre os desafios da pós-graduação: novas perspectivas sociais, conhecimento e poder. Revista Brasileira de Educação, Rio de Janeiro, v. 3, n. 18, p. 108-154, 2001.

GIL, A. C. Métodos e técnicas de pesquisa social, 5 ed. São Paulo: Atlas, 1999.

INSTITUTO BRASILEIRO DE GEOGRAFIA E ESTATÍTICA. Pesquisa Nacional por Amostra de Domicílios: síntese de indicadores 2014. Rio de Janeior: IBGE, 2015.

LEFF, E. Saber ambiental: sustentabilidade, racionalidade, complexidade, poder. Petrópolis, RJ: Vozes, 2001.

LOPES, M. M.; NEVES, F. F. A educação ambiental na modalidade à distância no Brasil e a investigação de políticas de avaliação qualitativa. Revista UNIARA, Araraquara, v. 17, n. 1, 2014.

LUCKESI, C. C. Filosofia da Educação, 2.ed. São Paulo: Ed. Cortez, 2011.

HACK, J. R. Introdução à educação à distância. Florianópolis: LLV/CCE/UFSC, 2011.

Revbea, São Paulo, V. 14, № 2: 234-251, 2019. 
MARTINS, K.; FROM, D. A. A importância da educação a distância na sociedade atual. ASSESSORITEC. Disponível em: <http://www.assessoritec. com.br/wp-content/uploads/sites/641/2016/12/Artigo-Karine.pdf>. Acesso em: 15 de mar. de 2018.

MICHELON, T.; LIRA, L. A. R.; RAZUCK, F. B. O sistema Universidade Aberta do Brasil: um estudo preliminar sobre a identificação dos fatores críticos da Gestão Integrada. Em rede: Revista de Educação a Distância, Porto Alegre, v. 3, n. 2, p. 213-226, 2016.

ROOS, A.; BECKER, E. L. S. Educação Ambiental e Sustentabilidade. Revista Eletrônica em Gestão, Educação e Tecnologia Ambiental, Santa Maria, v. 5, n. 5, p. 857-866, 2012.

SAID, F.; SANTOS, S. C. A importância da educação ambiental à distância na capacitação de professores de Geografia. Projeção e Docência, Brasília, v. 8, n. 1, p. 1-8, 2017.

SAVIANI, D. A pós-graduação em educação no Brasil: trajetória, situação atual e perspectivas. Revista Diálogo Educacional, Curitiba, v. 1, n. 1, p. 1-19, 2000.

SILVA, E. G.; PAULISTA, J. E. S.; DUTRA, M. L. S.; FREITAS, L. G.; BARREIRO, J. H. L. C. A pós-graduação e sua contribuição para a formação profissional dos administradores. In: Simpósio de Excelência em Gestão e Tecnologia, 6, 2009, Rezende. Anais eletrônicos...Rezende: RJ, 2009. Disponível em: <https://www.aedb.br/seget/arquivos/artigos09/412 Seget A pos graduacao na formacao do administrador.pdf>. Acesso em: 16 de mar. de 2018.

VENERAL, D. C. A contribuição da educação à distância na formação do cidadão no Estado Democrático de Direito. Ius Gentium, Curitiba, v. 7, n. 13, p. 255-264, 2013. 